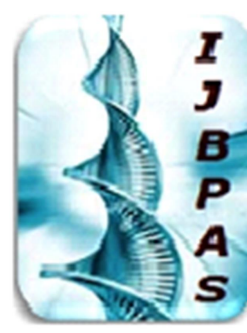

International Journal of Biology, Pharmaey and Allied Seiences (IJBPAS) 'A Bridge Betuben Caboratory and Q Q ander'

WwW.ibpas.com

\title{
A RARE MANIFESTATION OF MENINGITIS RETENTION SYNDROME IN EPSTEIN-BARR VIRUS INFECTION
}

\section{SANDHYA PC ${ }^{1^{*}}$, SARATH BHASKAR $\mathrm{S}^{4}$, PADMA $\mathrm{V}^{2}$, KAVI M.G $^{3}$, MURUGARAJ $^{4}$, ABHILASH NAIR ${ }^{4}$, SAKETH RAMINENI ${ }^{4}$ AND KANNAN MEERA DEVI ${ }^{4}$}

1: Senior Resident, Department of General Medicine, Sree Balaji Medical College and Hospital, Chrompet, Chennai-600044

2: Professor, Department of General Medicine, Sree Balaji Medical College and Hospital, Chrompet, Chennai-600044

3: Assistant, Professor-Department of General Medicine, Sree Balaji Medical College and Hospital, Chrompet, Chennai-600044

4: Junior Resident, Department of General Medicine, Sree Balaji Medical College and Hospital, Chrompet, Chennai-600044

*Corresponding Author: Sandhya PC: E Mail: sandhyapc.spe@gmail.com

Received 26 ${ }^{\text {th }}$ March 2021; Revised 27 ${ }^{\text {th }}$ April 2021; Accepted 24 ${ }^{\text {th }}$ May 2021; Available online $1^{\text {st }}$ Dec. 2021

\section{https://doi.org/10.31032/IJBPAS/2021/10.12.5793}

\section{ABSTRACT}

Meningitis-retention syndrome (MRS) is a rare disease in which aseptic meningitis is accompanied by urinary retention, which is not as easily understood as urinary tract infection. We present the case of a 65-year-old man with a fever and dysuria. At the time of hospitalization, the patient had no symptoms of meningitis, but symptoms of meningeal irritation appeared later in the course of the disease. Investigations revealed that this was a case of MRS due to Epstein-Barr virus. We should consider MRS when evaluating patients with fever and urinary retention, as dysuria may precede the symptoms of meningitis.

Keywords: Aseptic meningitis, acute urinary retention, Epstein-Barr virus, Meningitisretention syndrome 


\section{INTRODUCTION}

Meningitis retention syndrome (MRS) is a very rare disease that has been reported to be associated with herpes simplex virus type 2 (HSV-2) meningitis. The development of urinary retention in the context of meningitis and cerebrospinal fluid (CSF) pleocytosis, with the exception of lumbosacral radiculomyelitis is known as meningitis retention syndrome. But here in a 65 year old male MRS is manifested by Epstein-Barr virus.

\section{CASE REPORT}

A 65-year-old man was admitted to our hospital with fever and dysuria. Seven days before admission, she had a fever and doubts micturition difficulty. He was diagnosed to have a urinary tract infection and received oral antibiotic treatment. However, her fever did not go away, and slow urine steam and increased frequency of urination were often noted. The patient also had high blood pressure but was not taking any medications. She had 15 points on the Glasgow Coma Scale, body temperature $39.8 \circ \mathrm{C}$, blood pressure $150 / 82 \mathrm{mmHg}$, heart rate of 90 beats per minute, 12 respiratory rate per minute, and $\mathrm{SpO} 2$ of $99 \%$ in the air chamber. On physical examination, there was no abnormality in the recommended chest, no costovertebral angle flexion and no prostate tenderness. No abnormal sensory detection was detected. He had no neck stiffness. Brudzinski's and Kernig signs were absent. Investigations showed hyponatremia $(\mathrm{Na}$, $125 \mathrm{mEq} / \mathrm{l}$ ) but no inflammatory response (white blood cell count, 4,900 / $\mu$ l; C-active proteins, $0.1 \mathrm{mg} / \mathrm{dl}$ ). Urinalysis showed no evidence of infection and no source of infection was identified. The patient was admitted to hospital. The next day, he had difficulty in micturition and retention of urine in the bladder, following patient was catheterized. On the third day of hospitalization, the patient developed involuntary movements, nuchal stiffness, hyperreflexia of tendon reflexes, and pathological reflexes in both lower extremities. In CSF fluid analysis, cerebrospinal pressure was elevated to $260 \mathrm{~mm} \mathrm{CSF}$, the number of cells was significantly increased at 143 / micro liter by the dominant mononuclear cells, and the protein content was increased to $121 \mathrm{mg} /$ dl. These findings led to the discovery of urinary retention due to meningitisretention syndrome (MRS) with aseptic meningitis.

The differential diagnostic function of aseptic meningitis included a thorough polymerase chain reaction (PCR) test for Epstein - Barr (EBV) virus in the cerebro spinal fluid. EBV DNA measurements showed 920 copies / ml. The serum EBV 
antibody titer test showed a 10-fold increase in EBV VCA IgM, a 40-fold increase in EBV VCA IgG, and a positive anti-EBNA antibody, elevating an existing infection pattern. Therefore, EBV reactivation was identified as the cause of MRS. There were no findings or blood test data suggesting tuberculosis or any other virus, fungal, autoimmune or malignant aetiologies. After antiretroviral treatment and steroid pulse treatment, and the patient's symptoms are completely resolved.

\section{DISCUSSION}

This was the case for MRS due to EBV reactivation in a healthy adult with symptoms of meningitis followed by dysuria. MRS is a rare disease that includes aseptic meningitis and urinary retention but in most cases the cause is unknown [1]. Although its pathogenicity is not yet clear, MRS is similar to Elsberg syndrome in which urinary retention is caused by local viral infection through the herpes simplex virus [2]. Causes of urinary retention include sacral root injury due to direct inflammation of the bladder, transient sphincter damage, and post-infection damage to the internal and nervous system. It was reported that inflammation and pigmentation were associated with EBV infection [3]. Infection with EBV can be classified as lytic or latent. Transformation of B cells from a newly infected state results in the reactivation of EBV infection [4]. EBV is a lytic component and is particularly susceptible to infection, regardless of tissue location. Its rehabilitation can be highly recommended for patients with depressive disorders when the limit is exceeded. However, the dynamic and biological factors that cause or inhibit vivo regeneration are unknown [4]. Investigations into the case revealed that the cause of MRS was the recurrence of EBV. There are no reports of MRS to EBV relapse among weakened patients. Although the mechanisms of EBV regeneration in healthy individuals are unknown, damage to the central nervous system was reported in diseases caused by EBV reactivation, including meningitis [5].

Renewal may result in MRS. EBV VCA $\mathrm{IgG}$ detection is not as serious and specific as the detection of EBV DNA in spinal fluid. Therefore, quantitative testing of EBV DNA in spinal fluid is needed to confirm EBV infection. It can also be viewed in MRS cases of unknown origin.

In this patient, EBV VCA IgG was not detected in spinal fluid, although during recovery, the PCR test for EBV in spinal fluid changed from positive to negative. In the present case, dysuria, which precedes the symptoms of meningeal irritation, made it difficult to diagnose because it sought to 
be excreted without urinary tract infection.Frequent and persistent urination is often found in urinary tract infections. However, the same symptoms also suggest urine left in the bladder due to urinary retention. Therefore, a thorough abdominal examination and ultrasonography are essential for the diagnosis to be made.

\section{CONCLUSION}

Meningitis-retention syndrome (MRS) is a rare disease in which aseptic meningitis is accompanied by urinary retention, which is not as easily understood as urinary tract infection.MRS should be considered when examining patients with fever and urinary retention, as dysuria may precede the symptoms of meningitis. The presence of Epstein - Barr virus can also make MRS difficult.

\section{REFERENCES}

[1] Sakakibara R, Kishi M, Tsuyusaki Y, Taeno A, Tateno F, Uchiyama T, et al. Meningitis-retention syndrome: a review. Neurourol Urodyn., 2012; 32: 19-23.

[2] Savoldi F, Kaufmann T, Flanagan E, Toledano M, Weinshenker B. Elsberg syndrome: a rarely recognized cause of cauda equine syndrome and lower thoracic myelitis. Neurol Neuroimmunol Neuroinflamm., 2017; 4: e355.
[3] Sakakibara R, Uchiyama T, Liu Z, Yamamoto T, Ito T, Uzawa A, et al. Meningitis-retention syndrome: an unrecognized clinical condition. $J$ Neurol., 2005; 252: 1495-1499.

[4] Geng L, Wang X. Epstein-Barr virus-associated

lymphoproliferative disorders: experimental and clinical developments. Int J Clin Exp Med., 2015; 8: 14656-14671.

[5] Fujimoto H, Asaoka K, Imaizumi T, Ayabe M, Shoji H, Kaji M. Epstein-Barr virus infections of the central nervous system. Intern Med., 2003; 42: 33-40. 